\title{
Multimorbidity patterns of and use of health services by Swedish 85-year-olds: an exploratory study
}

Huan-Ji Dong ${ }^{1 *}$, Ewa Wressle ${ }^{1,2}$ and Jan Marcusson ${ }^{1,2}$

\begin{abstract}
Background: As life expectancy continues to rise, more elderly are reaching advanced ages ( $\geq 80$ years). The increasing prevalence of multimorbidity places additional demands on health-care resources for the elderly. Previous studies noted the impact of multimorbidity on the use of health services, but the effects of multimorbidity patterns on health-service use have not been well studied, especially for very old people. This study determines patterns of multimorbidity associated with emergency-room visits and hospitalization in an 85-year-old population.

Methods: Health and living conditions were reported via postal questionnaire by 496 Linköping residents aged 85 years (189 men and 307 women). Diagnoses of morbidity were reviewed in patients' case reports, and the local health-care register provided information on the use of health services. Hierarchical cluster analysis was applied to evaluate patterns of multimorbidity with gender stratification. Factors associated with emergency-room visits and hospitalization were analyzed using logistic regression models.

Results: Cluster analyses revealed five clusters: vascular, cardiopulmonary, cardiac (only for men), somatic-mental (only for men), mental disease (only for women), and three other clusters related to aging (one for men and two for women). Heart failure in men ( $\mathrm{OR}=2.4,95 \% \mathrm{Cl}=1-5.7)$ and women $(\mathrm{OR}=3,95 \% \mathrm{Cl}=1.3-6.9)$ as a single morbidity explained more variance than morbidity clusters in models of emergency-room visits. Men's cardiac cluster (OR $=1.6 ; 95 \%$ $\mathrm{Cl}=1-2.7)$ and women's cardiopulmonary cluster $(\mathrm{OR}=1.7,95 \% \mathrm{Cl}=1.2-2.4)$ were significantly associated with hospitalization. The combination of the cardiopulmonary cluster with the men's cardiac cluster ( $\mathrm{OR}=1.6,95 \% \mathrm{Cl}=1-2.4)$ and one of the women's aging clusters $(\mathrm{OR}=0.5,95 \% \mathrm{Cl}=0.3-0.8)$ showed interaction effects on hospitalization.

Conclusion: In this 85-year-old population, patterns of cardiac and pulmonary conditions were better than a single morbidity in explaining hospitalization. Heart failure was superior to multimorbidity patterns in explaining emergency-room visits. A holistic approach to examining the patterns of multimorbidity and their relationships with the use of health services will contribute to both local health care policy and geriatric practice.
\end{abstract}

Keywords: Multimorbidity, 85-year-old, Emergency-room visit, Hospitalization

\section{Background}

A growing number of studies have noted that an increasing number of chronic conditions is resulting in a substantial rise in the use of health service resources, and associated expenses will continue to rise [1-5]. Among the younger population, the predominant picture is that women report more chronic conditions and

\footnotetext{
* Correspondence: huanji.dong@liu.se

${ }^{1}$ Department of Clinical and Experimental Medicine, Division of Geriatrics, Faculty of Health Sciences, Linköping University, 58185 Linköping, Sweden Full list of author information is available at the end of the article
}

seek more health care than men [6,7]. In contrast, among the population of 85-year-olds, researchers found that women use the same or fewer health services than men $[8,9]$. However, these studies conducted no further analysis with regard to underlying factors in relation to the use of health services. In 2007, we started a population-based project on 85-year-old residents in Linköping municipality (Elderly in Linköping Screening Assessment, ELSA 85, Sweden). We studied morbidity and multimorbidity (at least two chronic diseases), living conditions, and visits to the general practitioner
C Biomed Central

(c) 2013 Dong et al.; licensee BioMed Central Ltd. This is an open access article distributed under the terms of the Creative Commons Attribution License (http://creativecommons.org/licenses/by/2.0), which permits unrestricted use, distribution, and reproduction in any medium, provided the original work is properly cited. 
(GP) in relation to in-patient hospitalization [10]. Factors associated with in-patient care included an increased number of GP visits, more assistive technology, community assistance and multimorbidity [10]. Examining some of these factors, gender has been shown to influence several of the covariates; e.g., the use of assistive technology [11] and multimorbidity [12]. Moreover, studies on multimorbidity defined by a cut-off point did not reflect how the morbidities relate to each other. As reported by John et al. [13] and applied by Marengoni et al. [14] and Formiga et al. [15], some co-occurrences exceed a level expected by chance alone. Therefore, studies on multimorbidity may have to be explored in a more complex context; e.g., the effects of gender and clustering of diseases can be considered.

In Sweden, public resources are state controlled. Provisions for community services, assistive technology, and health care are funded by taxes and are universally available according to individual needs [16]. Individuals pay 150 SEK (\$23) for a visit to a GP, 300 SEK (\$46) to access emergency care and up to 80 SEK $(\$ 12)$ per day for a hospital stay [17]. With a GP referral to an emergency room (ER), a compensation payment of 150 SEK instead of 300 SEK is charged. The base of the health care system is primary care. Linköping, the largest town in Östergötland County, has a university hospital in which the primary care and the hospital disciplines have shared patient records via an electronic system (Cosmic) since 2007. A referral from a GP is mandatory for patients to visit a specialist whenever specialized health care is required. In practice, younger patients usually refer themselves to the ER whereas it is more common that older patients are referred after visiting their caregivers in primary care. The GP plays an important role in the further care of patients. We therefore consider consultations with a GP as a potential factor related to both ER visits and hospitalization.

The aim of the present study is to further examine the complexity of multimorbidity in relation to the use of health services. We conducted analyses with gender stratification to investigate morbidity patterns and their associations with ER visits and hospitalization. Nationwide, these two outcomes account for substantial spending in health care.

\section{Methods}

\section{Sample}

All eligible inhabitants were individuals born in 1922 and residing in Linköping municipality, Sweden $(\mathrm{n}=$ 650; 235 men and 415 women). The inclusion period for this study was one year (between March 2007 and March 2008). Postal questionnaires and invitation letters were posted at the beginning of each month during the inclusion period. The letters invited individuals to participate in the study 2 months after their $85^{\text {th }}$ birthday.
In the case of no response to an invitation letter, a reminder was sent after 2 weeks. All responses were sent to the Department of Geriatric Medicine, Linköping University Hospital.

\section{Postal questionnaire}

The postal questionnaire included questions on sociodemographics (housing, marital status, living situation, level of education, and previous occupation). Working status, measured by previous occupation, was classified into the following categories: low (blue collar), intermediate (white collar), and high (self-employed or academic profession) [18]. For non-participants, information about housing type was checked using the registered address.

The individuals were asked about their use of assistive technology (wheelchair, walker, crutch, vertically adjustable bed, bath/shower technology, adapted toilet, portable toilet, and gripper) and assistance needed (community assistance, transportation service, personal alarm, and food delivery). To evaluate the individual's self-rated health, a visual analogue scale (VAS) was used ranging from 0 (worst imaginable health status) to 100 (best imaginable health status) [19]. Finally, the individuals provided information on the presence of chronic diseases.

\section{Morbidities and use of health services}

The patients' medical records are part of the electronic medical report system of the County Council of Östergötlands containing all health-care records (both inpatient and outpatient data) for all citizens of Linköping and the County of Östergötland. Older medical history was also checked in older paper medical records kept for all individuals at the central hospital archives of Linköping University Hospital. This procedure was performed by an experienced geriatrician. The research team compared the documentation in the medical records with the selfreported information in terms of diseases and drug treatments. The self-reported information was the response to two separate questions in the postal questionnaire, regarding chronic and acute medical conditions/diseases. All diseases/conditions indicated were noted for each patient. A disease or condition was only registered if there was clear documentation of the disease and its treatment, regardless of the patients' self-reports. The $10^{\text {th }}$ version of the International Classification of Diseases (ICD-10) was used [20]. The presence of chronic disease was then registered if the disease fulfilled one or more of three criteria: the disease was permanently present, the disease was caused by an irreversible pathological condition, and treatment for the disease required rehabilitation or a long period of care. A predetermined list was made for disease categories: cardiovascular disease, cerebrovascular disease, respiratory disease, musculoskeletal disease, mental disease, neurological disease, digestive disorders, urological disorders, 
endocrine disease, hematological disorders, autoimmune disease, infection, skin changes and malignancy (solid and blood). In the present study, we chose a prevalence of more than $5 \%$ as the criterion for a common morbidity.

Data for the use of health services by each individual were provided by the local health care register. The records included visits to a GP, visits to an ER and hospitalization during 2007.

\section{Statistical analyses}

The SPSS Statistical package (version 20.0) was used for the data analyses. The differences between men and women were assessed using the Student's t-test for normally distributed continuous variables, Mann-Whitney U-test for non-Gaussian distributed variables, and Pearson Chi-square test for categorical variables. Effect size was calculated using Cohen's d for Student's t-test, rank-biserial correlation coefficient $\mathrm{r}\left(\mathrm{r}_{\mathrm{rb}}\right)$ for the Mann-Whitney U-test and Cramér's phi $\left(\varphi_{c}\right)$ for the Pearson Chi-square test.

A hierarchical cluster dendrogram was generated using Yule's $\mathrm{Q}$ as the similarity measure between clusters, with a higher value indicating greater similarity measurement. Yule's Q correlation matrix was calculated as a transformation of the odds ratio (OR) between two variables from $(0$ to infinity) to $(-1$ to +1$): \mathrm{Q}=(\mathrm{OR}-1) /(1+\mathrm{OR})[21,22]$. We chose the average linkage between groups for the agglomeration because this method takes into account the cluster structure and is relatively robust [23].

To determine predictors of an ER visit or hospitalization, logistic regression was performed with a forward stepwise method (using a likelihood ratio, with entrance/exit tolerances of 0.05/0.10). Model 1 used all single morbidities as candidate variables. Model 2 substituted cluster scores for single morbidities. Interaction of morbidity clusters was included in Model 3. According to John et al. [13], the effects of multimorbidity patterns are evaluated in the form of cluster scores (a count of all morbidities in one cluster) and their interactions (multiplication of two cluster scores, to determine if the clusters' effects are dependent on each other). Other candidate variables such as socio-demographic factors, individuals' needs, self-rated health, and the number of visits to a GP were included for model fitting [10]. Collinearity and correlation were analyzed before model fitting. Marital status and living situations were not included concurrently in the analysis owing to high collinearity $(r>0.6)$. The Nagelkerke $R^{2}$ (Cox and Snell $R^{2}$ adjusted, range $0-1$ ) was used to estimate the amount of variance in the outcomes explained by the predictors [24].

\section{Ethical aspects}

The local Ethical Committee approved the study (Dnr141-06, Linköping), and written informed consent was obtained from all participants and/or their relatives. All participants were informed that taking part in the project was voluntary and participation could be terminated at any moment.

\section{Results \\ Completeness, representativeness, and sample characteristics}

Twelve individuals died before completing the questionnaire and $52(8 \%)$ individuals did not respond to the invitation letter even after the reminder. A total of 496 individuals (189 men and 307 women, 76\%) completed the questionnaire. No gender difference was found between participants and non-participants (men vs. women, 46 vs. $\left.108, x^{2}=3.452, d f=1, p=0.063\right)$. A larger proportion of non-participants $(45 / 154,30 \%)$ than participants (55/496, 11\%) lived in sheltered accommodation/nursing homes $\left(x^{2}=29.679, \mathrm{df}=1, \mathrm{p}<0.001\right)$. Table 1 summarizes baseline characteristics of the participants. More women than men were living by themselves, had lower education, had lower working status, and used more assistive technology and assistance. Despite the statistical significance, the differences correspond to a small effect size. The most frequently used assistive technology-a walker-was related to improving mobility ( $40 \%$ of all participants; men vs. women, $23 \%$ vs. $52 \%$ ). Food delivery was the only item of assistance reported by few elderly (men vs. women, $10 / 189$ vs. $26 / 307, x^{2}=1.64, \mathrm{df}=1, \mathrm{p}=0.2$ ). The elderly perceived themselves to be in general good health (score of self-rated health $\geq 60$ ) and men were even more positive than women in this study. During the observation year, over three-quarters of the elderly (men vs. women, 138 vs. $242, \mathrm{X}^{2}=2.205, \mathrm{df}=1, \mathrm{p}=0.138$ ) had visited a GP, but less than one-third had visited an ER or been hospitalized. In absolute numbers, almost twice as many women as men visited an ER or had been hospitalized.

Table 2 gives the rates of most common morbidities according to gender. The significant differences were the greater proportions of men with myocardial infarction and malignancy and the greater proportions of women suffering urinary incontinence, affective disease, dementia and osteoporosis.

\section{Morbidity clusters}

Using the measure of similarity (Yule's Q) and the cluster algorithm (average linkage between groups), we found a large decline in agglomerative coefficients between 0.2 and 0.3 , indicating an increase in heterogeneity between clusters. A cut-off in this range of coefficients provided three-five clusters for men (Figure 1) and foursix clusters for women (Figure 2). A higher cut-off coefficient resulted in several smaller clusters whereas a lower cut-off coefficient provided larger clusters. We evaluated that a five-cluster structure identifies most clinically 
Table 1 Characteristics of the participants

\begin{tabular}{|c|c|c|c|c|}
\hline Characteristics & $\begin{array}{l}\text { Men } \\
n=189\end{array}$ & Women $\mathrm{n}=\mathbf{3 0 7}$ & $p$-value (statistic) & Effect size \\
\hline Type of housing, $\mathrm{n}(\%)$ & & & $0.079\left(x^{2}=3.08, d f=1\right)^{a}$ & $\varphi_{c}=0.079$ \\
\hline Ordinary housing & $174(92)$ & $267(87)$ & & \\
\hline Sheltered accommodation/Nursing home & $15(8)$ & $40(13)$ & & \\
\hline Marital status, n (\%) & & & $<0.001\left(x^{2}=56.78, d f=1\right)^{a}$ & $\varphi_{c}=0.34$ \\
\hline Married/Cohabitated & $142(75)$ & $124(40)$ & & \\
\hline Widowed/Divorced/Unmarried & $47(25)$ & $183(60)$ & & \\
\hline Living situation, $n(\%)$ & & & $<0.001\left(x^{2}=61.17, d f=1\right)^{a}$ & $\varphi_{c}=-0.35$ \\
\hline Alone & $68(36)$ & $220(72)$ & & \\
\hline With others & $121(64)$ & $87(28)$ & & \\
\hline Level of education, n (\%) & & & $<0.001\left(x^{2}=6.57, d f=1\right)^{a}$ & $\varphi_{c}=-0.18$ \\
\hline$\leq 7$ years & $97(52)$ & $188(64)$ & & \\
\hline$>7$ years & $89(48)$ & $106(36)$ & & \\
\hline Working status, n (\%) & & & $0.004\left(x^{2}=10.83, d f=2\right)^{a}$ & $\varphi_{c}=-0.15$ \\
\hline Low (blue collar) & $81(44)$ & $174(59)$ & & \\
\hline Intermediate (white collar) & $85(46)$ & 103(35) & & \\
\hline High (self-employed or academic profession) & $17(9)$ & $16(6)$ & & \\
\hline Use of assistive technology, $\mathrm{n}(\%)$ & $80(43)$ & $212(70)$ & $<0.001\left(x^{2}=34.33, d f=1\right)^{a}$ & $\varphi_{c}=0.26$ \\
\hline No. of used assistive technology, Median, (IQR) & $0(0-2)$ & $2(0-3)$ & $<0.001(U=20116, d f=490)^{b}$ & $r_{r b}=0.26$ \\
\hline Assistance needed, n (\%) & $75(40)$ & $209(68)$ & $<0.001\left(x^{2}=37.11, d f=1\right)^{a}$ & $\varphi_{c}=0.28$ \\
\hline No. of used assistance service, Median, (IQR) & $0(0-1)$ & $1(1-2)$ & $<0.001(U=19001, d f=488)^{b}$ & $r_{r b}=0.3$ \\
\hline Self-rated Health (range 0-100), Mean \pm SD & $69 \pm 19$ & $65 \pm 20$ & $0.018(t=-2.37, d f=435)^{c}$ & Cohen's $d=0.21$ \\
\hline No. of GP visits, Median (IQR) & $1(0-3)$ & $2(1-3)$ & $0.057(U=26119, d f=494)^{b}$ & $r_{r b}=0.09$ \\
\hline Any visit to $\mathrm{ER}, \mathrm{n}(\%)$ & $55(31)$ & $95(29)$ & $0.664\left(x^{2}=0.19, d f=1\right)^{a}$ & $\varphi_{c}=0.02$ \\
\hline Any in-patient hospitalization, n (\%) & $44(25)$ & $79(23)$ & $0.539\left(x^{2}=0.38, d f=1\right)^{a}$ & $\varphi_{c}=0.03$ \\
\hline
\end{tabular}

GP, General practitioner; ER, Emergency Room;

Number of subjects, \% of subjects, means with standard deviations (SD), and median with interquartile range (IQR) of variables are shown.

${ }^{a}$ Pearson Chi-square, ${ }^{b}$ Mann-Whitney U Test; ${ }^{c}$ Student's t test; $\varphi_{c}$ : Cramér's phi; $r_{r b}$ : rank-biserial correlation coefficient $r$.

meaningful multimorbidity for both genders. To show the magnitude of similarity between clusters/variables, we took Cluster 1 as an example and read off the distance for each node in Cluster 1 in the dendrograms.

In the men's dendrogram, Cluster 1 was identified as a vascular cluster. Heart and pulmonary conditions were structured in Cluster 2 (cardiopulmonary) and Cluster 4 (cardiac). Two clusters were related to aging: Cluster 3 containing a somatic-mental combination and Cluster 5 aggregating malignancy with osteoarthritis.

In the women's dendrogram, the vascular cluster (Cluster 1) was similar to that in the men's dendrogram but included hyperlipidemia. The cardiopulmonary cluster (Cluster 3) was larger than that of men; myocardial infarction, arrhythmia, and heart failure were connected, and chronic obstructive pulmonary disease (COPD)/asthma was associated with osteoporosis. There were combinations related to aging in Cluster 2 where urinary incontinence was combined with osteoarthritis and in Cluster 4 where malignancy and thyroid dysfunction were merged.
Finally, a mental disease cluster (Cluster 5) comprised dementia and affective disorders.

\section{Factors associated with an ER visit}

As illustrated in Tables 3 and 4, single-morbidity models (Model 1) explained more variance than did morbiditycluster models (Model 2). Heart failure was the most significant factor associated with ER visits for both men and women (Model 1). The men's cardiac cluster (Cluster 4) and women's cardiopulmonary cluster (Cluster 3 ) led to an increased likelihood of an ER visit (Model 2). Model 3 for cluster interaction was not constructed, because there was no significant cluster interaction.

\section{Factors associated with hospitalization}

Morbidity clustering (Model 2) and cluster interactions (Model 3) explained more variance than the singlemorbidity model (Model 1) (Tables 5 and 6).

No single morbidity was significantly related to men's hospitalization. The cardiac cluster (Cluster 4) and its 
Table 2 Prevalence of diagnosed chronic diseases $(n=496)$

\begin{tabular}{|c|c|c|c|c|}
\hline & Total n (\%) & Men n (\%) & Women n (\%) & $p$-value (statistic) \\
\hline Hypertension & $250(50.4)$ & $97(51.3)$ & $153(49.8)$ & $0.748\left(\chi^{2}=0.10\right)$ \\
\hline Hyperlipidemia & 107 (21.6) & $53(28)$ & $54(17.6)$ & $0.006\left(\chi^{2}=7.56\right)$ \\
\hline Urinary incontinence & $103(20.8)$ & $19(10.1)$ & $84(27.4)$ & $<0.001\left(\chi^{2}=21.3\right)$ \\
\hline Arrhythmia & $78(15.7)$ & $29(15.3)$ & $49(16)$ & $0.115\left(\chi^{2}=0.03\right)$ \\
\hline Heart failure & $75(15.1)$ & $33(17.5)$ & $42(13.7)$ & $0.254\left(\chi^{2}=1.30\right)$ \\
\hline Diabetes & $75(15.1)$ & $27(14.3)$ & 48 (15.6) & $0.684\left(\chi^{2}=0.17\right)$ \\
\hline Stroke & $58(11.7)$ & $23(12.2)$ & $35(11.4)$ & $0.796\left(\chi^{2}=0.07\right)$ \\
\hline Myocardial infarction & $55(11.1)$ & $30(15.9)$ & $25(8.1)$ & $0.008\left(\chi^{2}=7.09\right)$ \\
\hline Affective diseases & $60(12.1)$ & $14(7.4)$ & $46(15)$ & $0.012\left(\chi^{2}=6.32\right)$ \\
\hline Malignancy & $50(10.1)$ & $28(14.3)$ & $22(7.2)$ & $0.006\left(\chi^{2}=7.48\right)$ \\
\hline Asthma or COPD & $45(9.1)$ & $20(10.6)$ & $25(8.1)$ & $0.358\left(\chi^{2}=0.84\right)$ \\
\hline Osteoarthritis & $39(8.3)$ & $11(5.8)$ & $28(9.8)$ & $0.185\left(\chi^{2}=1.76\right)$ \\
\hline Thrombosis or PVD & $35(7.1)$ & $14(7.9)$ & $21(6.5)$ & $0.811\left(\chi^{2}=0.06\right)$ \\
\hline Dementia & $33(6.7)$ & $7(3.7)$ & $26(8.5)$ & $0.039\left(\chi^{2}=4.28\right)$ \\
\hline Thyroid dysfunction & $33(6.7)$ & $8(4.2)$ & $25(8.1)$ & $0.09\left(\chi^{2}=2.88\right)$ \\
\hline Osteoporosis & $24(4.8)$ & $1(0.5)$ & $23(7.5)$ & $<0.001\left(\chi^{2}=12.32\right)$ \\
\hline Multimorbidity ( $\geq 2$ chronic diseases) & 339 (68.3) & $134(70.8)$ & $205(66.8)$ & $0.338\left(\chi^{2}=0.92\right)$ \\
\hline
\end{tabular}

COPD, Chronic Obstructive Disease; $P V D$, Periphery Vascular Disease.

Data were analyzed using Chi-square, $\mathrm{df}=1$.

combination with the cardiopulmonary cluster (Cluster 2) were significant with respect to hospitalization. The variance had an overall increase of 3.2\% from Model 1 to Model 3.

For women, heart failure was positively associated with hospitalization and urinary incontinence had an inverse association. The clusters (Cluster 2 and 3) including these two morbidities appeared in Model 2. In Model 3, the cardiopulmonary cluster (Cluster 3 ) had a stronger effect than that in Model 2. However, Cluster 2 dampened the effect via a cluster interaction with Cluster 3.

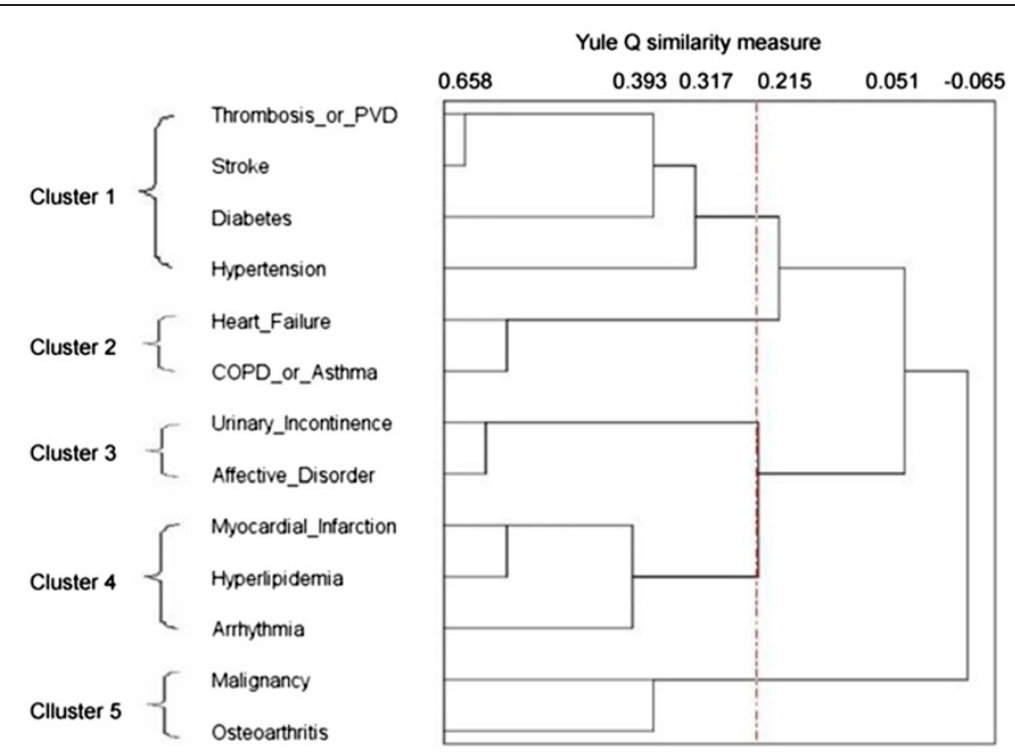

Figure 1 Men's morbidity clusters. In the tree diagram, the distance between two clusters (or variables) is calculated according to the measure of similarity (Yule's Q) and the cluster algorithm (average linkage between groups). The shorter the distance, the closer are the clusters. Three to five clusters are obtained by shifting the cut-off (vertical line) between $Q$ values of 0.2 and 0.3 . We evaluate that a five-cluster solution identifies most clinically meaningful multi-morbidity. The agglomerative coefficients given to the terminal node in each cluster are: Cluster 1, 0.317 (OR 1.9); Cluster 2, 0.587 (OR 3.8); Cluster 3, 0.62 (OR 4.3); Cluster 4, 0.581 (OR 3.8); Cluster 5, 0.393 (OR 2.3). 


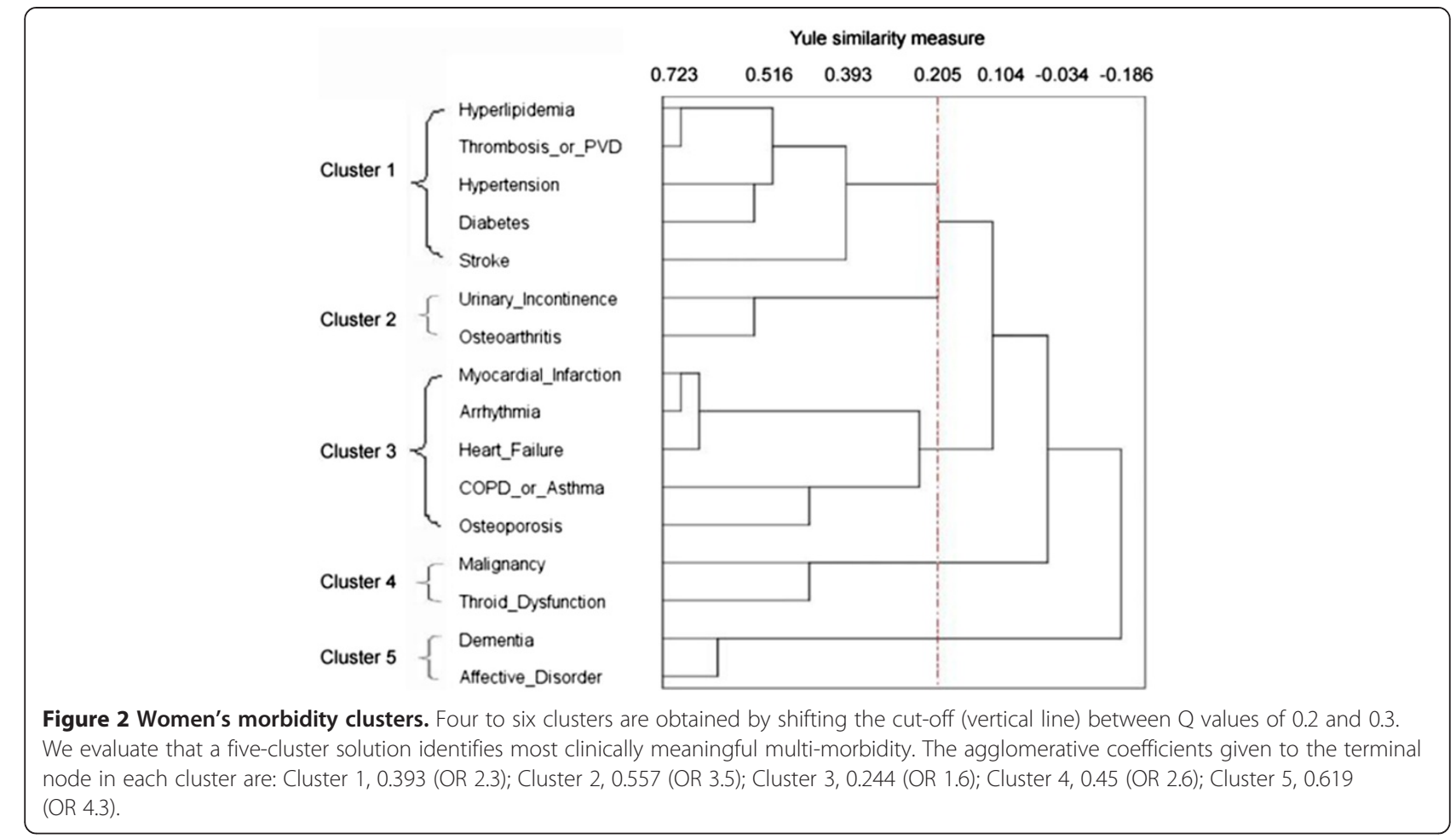

\section{Discussion}

Many very old people inevitably need daily assistance and health service as a result of functional impairment and illness. The existence of multimorbidity has a complex effect on the use of health services. Unfortunately, the complexity and conjoint effects are often overlooked. In the present study, rather than just focusing on a single diagnosis, we studied multimorbidity patterns in relation to the use of health services. Our major findings were that patterns of cardiac and pulmonary conditions were better associated than any single morbidity with hospitalization and that heart failure as a single morbidity was better associated than multimorbidity patterns with ER visits. Gender stratification simplified the comprehensive role played by gender in morbidity prevalence and related factors associated with the use of health services.

\section{Morbidity clusters}

Beyond the statistical results from cluster analysis, some patterns of multimorbidity are expected and supported with findings from other studies. First, in Cluster 1, all morbidities shared the common pathophysiological mechanism of vascular disorders except diabetes. However, we still have good reason to believe that in the long run very old people who have complications associated with diabetes have other co-occurring vascular morbidities. Similar findings were also reported by previous studies using cluster analysis $[13,15]$. Second, the cardiopulmonary cluster is another expected cluster. Heart failure in the men's cardiopulmonary cluster was only related to COPD/asthma. The cluster was closer to vascular diseases (Cluster 1) than the cardiac cluster (Cluster 4). The women's cardiopulmonary cluster contained all

Table 3 Association of single morbidity and morbidity clusters with ER visits in men

\begin{tabular}{lllr}
\hline \multicolumn{2}{c}{ Model $\mathbf{1}$ single morbidity } & & \multicolumn{2}{c}{ Model $\mathbf{2}$ morbidity clusters } \\
\hline Predictors & $\mathrm{OR}(95 \% \mathrm{Cl}) ; p$ & Predictors & OR (95\% Cl); $p$ \\
Heart failure & $2.4(1-5.7) ; 0.043$ & Cluster 4 & $1.6(1-2.5) ; 0.036$ \\
No. of GP visits & $1.3(1.1-1.5) ; 0.006$ & No. of GP visits & $1.3(1.1-1.5) ; 0.004$ \\
Nagelkerke R & 0.135 & Nagelkerke $\mathrm{R}^{2}$ & 0.11 \\
\hline
\end{tabular}

Odds Ratios (ORs) with 95\% Confidence Intervals (Cl) in parentheses and $p$-value are shown.

Cluster4: hyperlipidemia, myocardial infarction, and arrhythmia.

Predictors excluded in model 1: type of housing, marital status, level of education, working status, no. of used assistive tecknology, no. of used assistance service, self-rated health, thrombosis/PVD, stroke, diabetes, hypertension, COPD/asthma, urinary incontinence, affective disorder, myocardial infarction, hyperlipidemia, arrythmia, malignancy, and osteoarthritis.

Predictors excluded in model 2: type of housing, marital status, level of education, working status, no. of used assistive tecknology, no. of used assistance service, self-rated health, Cluster 1, Cluster 2, Cluster 3 and Cluster 5. 
Table 4 Association of single morbidity and morbidity clusters with ER visits in women

\begin{tabular}{lllr}
\hline \multicolumn{2}{c}{ Model 1 single morbidity } & \multicolumn{1}{c}{ Model 2 morbidity clusters } \\
\hline Predictors & OR $(95 \%$ Cl); $p$ & Predictors & OR $(95 \%$ Cl); $p$ \\
Low working status & reference & Cluster 3 & $1.5(1.1-2) ; 0.021$ \\
Middle working status & $2.2(1.1-4.1) ; 0.018$ & No. of GP visits & $1.4(1.2-1.6) ;<0.001$ \\
High working status & $3.5(1.1-11.3) ; 0.036$ & \\
Heart failure & $3(1.3-6.9) ; 0.01$ & \\
Arrhythmia & $2.2(1-4.8) ; 0.05$ & \\
Diabetes & $0.3(0.1-0.9) ; 0.027$ & \\
No. of GP visits & $1.3(1.1-1.6) ;<0.001$ & Nagelkerke $R^{2}$ & 0.143 \\
Nagelkerke $R^{2}$ & 0.219 &
\end{tabular}

Odds Ratios (ORs) with 95\% Confidence Intervals $(\mathrm{Cl})$ in parentheses and $p$-value are shown.

GP: General Practioner;

Cluster3: myocardial infarction, arrhythmia, heart failure, COPD/asthma, and osteoporosis.

Predictors excluded in model 1: type of housing, marital status, level of education, no. of used assistive tecknology, no. of used assistance service, self-rated health, hyperlipidemia, thrombosis/PVD, hypertension, stroke, urinary incontinence, osteoarthritis, myocardial infarction, COPD/asthma, osteoporosis, malignancy, thyroid dysfunction, dementia, and affective disorder.

Predictors excluded in model 2: type of housing, marital status, level of education, working status, no. of used assistive tecknology, no. of used assistance service, self-rated health, Cluster 1, Cluster 2, Cluster 4, and Cluster 5.

heart conditions as well as COPD/asthma. COPD/ asthma was first linked to osteoporosis, suggesting osteoporosis was a consequence of long-term treatment of corticosteroids for COPD/asthma patients $[25,26]$. This cardiopulmonary pattern was also reported by Marengoni et al. [14] and John et al. [13] but with no gender specificity. A third finding is the clusters of mental diseases. The women's mental and somatic morbidities were independent of each other. Comparatively, men had a somatic-mental cluster as only affective disorder was included in the analysis. Its association with urinary incontinence was not formally documented in any psychiatric journal according to Vasudev et al. [27] even though the impact of urinary incontinence on mental health has been reported by other researchers [28,29].

Some morbidities emerged in the same cluster but did not seem to follow pathophysiological pathways such as urinary incontinence and osteoarthritis (Cluster 2 in women). In women, osteoarthritis-related disability may negatively affect urinary control [30]. Another exception is the comorbidity of malignancy. It is difficult to anticipate which comorbidity coexists with a certain type of malignancy, since cancer patients manifest multiple health problems [31]. One reflection from daily clinical practice is that patients with a malignancy diagnosis usually have received complete clinical and laboratory examinations, and

Table 5 Association of single morbidity, morbidity clusters, and cluster interactions with hospitalization in men

\begin{tabular}{|c|c|c|c|c|c|}
\hline \multicolumn{2}{|c|}{$\begin{array}{l}\text { Model1 } \\
\text { single morbidity }\end{array}$} & \multicolumn{2}{|c|}{$\begin{array}{c}\text { Model } 2 \\
\text { morbidity clusters }\end{array}$} & \multicolumn{2}{|c|}{$\begin{array}{c}\text { Model } 3 \\
\text { interactions between morbidity clusters }\end{array}$} \\
\hline Predictors & OR $(95 \% \mathrm{Cl}) ; p$ & Predictors & $\mathrm{OR}(95 \% \mathrm{Cl}) ; p$ & Predictors & OR $(95 \% \mathrm{Cl}) ; p$ \\
\hline $\begin{array}{l}\text { No. of used assistive } \\
\text { technology }\end{array}$ & $\begin{array}{l}1.6(1.2-2) \\
<0.001\end{array}$ & $\begin{array}{l}\text { No. of used assistive } \\
\text { technology }\end{array}$ & $\begin{array}{l}1.6(1.3-2) \\
<0.001\end{array}$ & $\begin{array}{l}\text { No. of used assistive } \\
\text { technology }\end{array}$ & $\begin{array}{l}1.6(1.2-2) \\
<0.001\end{array}$ \\
\hline \multirow[t]{2}{*}{ No. of GP visits } & $\begin{array}{l}1.2(1.0-1.5) \\
0.028\end{array}$ & No. of GP visits & $\begin{array}{l}1.2(1.0-1.5) \\
0.032\end{array}$ & No. of GP visits & $\begin{array}{l}1.2(1.0-1.5) \\
0.049\end{array}$ \\
\hline & & Cluster 4 & $\begin{array}{l}1.6(1.0-2.7) ; \\
0.048\end{array}$ & Cluster $2^{*}$ Cluster 4 & $\begin{array}{l}1.6(1.0-2.4) ; \\
0.042\end{array}$ \\
\hline Nagelkerke $R^{2}$ & 0.188 & Nagelkerke $R^{2}$ & 0.219 & Nagelkerke $R^{2}$ & 0.22 \\
\hline
\end{tabular}

Odds Ratios (ORs) with 95\% Confidence Intervals (CI) in parentheses and $p$-values are shown.

GP, General practitioner;

Cluster 2: heart failure, asthma/COPD; Cluster 4: hyperlipidemia, myocardial infarction, and arrhythmia;

Predictors excluded in model 1: type of housing, marital status, level of education, working status, no. of used assistance service, self-rated health, thrombosis/ PVD, stroke, diabetes, hypertension, heart failure, COPD/asthma, urinary incontinence, affective disorder, myocardial infarction, hyperlipidemia, arrythmia, malignancy, and osteoarthritis.

Predictors excluded in model 2: type of housing, marital status, level of education, working status, no. of used assistance service, self-rated health, Cluster 1, Cluster 2, Cluster 3, and Cluster 5.

Predictors excluded in model 3: type of housing, marital status, level of education, working status, no. of used assistance service, self-rated health, Cluster 1 , Cluster 2, Cluster 3, Cluster 4, Cluster 5, Cluster $1 *$ Cluster 4, Cluster 3*Cluster 4, Cluster 5*Cluster 4. 
Table 6 Association of single morbidity, morbidity clusters, and cluster interactions with hospitalization in women

\begin{tabular}{|c|c|c|c|c|c|}
\hline \multicolumn{2}{|c|}{$\begin{array}{c}\text { Model } 1 \\
\text { single morbidity } \\
\end{array}$} & \multicolumn{2}{|c|}{$\begin{array}{c}\text { Model } 2 \\
\text { morbidity clusters }\end{array}$} & \multicolumn{2}{|c|}{$\begin{array}{c}\text { Model } 3 \text { I } \\
\text { interactions between morbidity clusters }\end{array}$} \\
\hline Predictors & OR $(95 \% \mathrm{Cl}) ; p$ & Predictors & OR $(95 \% \mathrm{Cl}) ; p$ & Predictors & OR $(95 \% \mathrm{Cl}) ; p$ \\
\hline No. of GP visits & $1.4(1.2-1.6) ;<0.001$ & No. of GP visits & $1.3(1.1-1.6) ;<0.001$ & Sheltered accommodation/ Nursing home & $2.5(1.0-5.9) ; 0.044$ \\
\hline Heart failure & $3.4(1.6-7.3) ; 0.002$ & Cluster 2 & $0.4(0.2-0.8) ; 0.006$ & No. of GP visits & $1.4(1.2-1.6) ;<0.001$ \\
\hline \multirow[t]{2}{*}{ Urinary incontinence } & $0.4(0.2-0.8) ; 0.012$ & Cluster 3 & $1.7(1.2-2.4) ; 0.004$ & Cluster 3 & $2.3(1.5-3.5) ;<0.001$ \\
\hline & & & & Cluster $2^{*}$ Cluster 3 & $0.5(0.3-0.8) ; 0.005$ \\
\hline Nagelkerke $\mathrm{R}^{2}$ & 0.19 & Nagelkerke $\mathrm{R}^{2}$ & 0.193 & Nagelkerke $\mathrm{R}^{2}$ & 0.213 \\
\hline
\end{tabular}

Odds Ratios (ORs) with 95\% Confidence Intervals (Cl) in parentheses and $p$-values are shown.

GP, General practitioner;

Cluster 2: incontinence, osteoarthritis; Cluster 3: myocardial infarction, arrhythmia, heart failure, asthma/COPD, and osteoporosis.

Predictors excluded in model 1: type of housing, marital status, level of education, working status, no. of used assistive tecknology, no. of used assistance service, self-rated health, malignancy, hypertension, myocardial infarction, arrythmia, hyperlipidemia, COPD/asthma, diabetes, dementia, affective disorder, thyroid dysfunction, osteoporosis, osteoarthritis, thrombosis/PVD, and stroke.

Predictors excluded in model 2: type of housing, marital status, level of education, working status, no. of used assistive tecknology, no. of used assistance service, self-rated health, Cluster 1, Cluster 4, and Cluster 5.

Predictors excluded in model 3: marital status, level of education, working status, no. of used assistive tecknology, no. of used assistance service, self-rated health, Cluster 1, Cluster 2, Cluster 4, Cluster 5, Cluster 1*Cluster 2, Cluster 4* Cluster 2, Cluster $5^{*}$ Cluster 2, Cluster 1* Cluster 3, Cluster 4*Cluster 3, Cluster $5^{*}$ Cluster 3 .

therefore, some comorbidity such as osteoarthritis and thyroid dysfunction would not be missed. Another hypothesis is based on the selection of survivals of concurrent ailments. Among cancer patients, some co-occurrences (e.g., severe heart disease) are more likely than others (e.g., osteoarthritis) to cause a high risk of mortality.

\section{Multimorbidity patterns associated with ER visits and hospitalization}

Patients using ER services are heterogeneous with respect to the medical services they require. The slightly lower $\mathrm{R}^{2}$ in the morbidity cluster models reveals that the selected morbidity cluster (men's cardiac cluster and women's cardiopulmonary cluster) did not improve explained variance. In other words, single-morbidity models are more precise in predicting ER visits. A reflection of real clinical practice is that a single morbidity (e.g., heart failure) as a medical condition may already be enough for an ER visit. Unexpectedly, several common morbidities such as COPD/asthma, stroke and even myocardial infarct were not significantly related to ER visits in this study population. Seemingly, in this very old population, these diagnoses were not clearly related to exacerbations or new attacks, but more possibly suggested permanent chronic conditions in patients' medical records.

In terms of hospitalization, our results are consistent with those of other studies that multimorbid patients were more likely to be hospitalized [32,33]. The advantage of our approach is that morbidity cluster and cluster interaction models provide more information. Unlike the counts of morbidities, where all morbidities are equally scored irrespective of their inner relationship, morbidity cluster and cluster interaction models address what morbidity cluster was the leading cause of hospitalization. For both men and women, the cardiac and pulmonary condition was a major factor associated with hospitalization. For women, urinary incontinence and its comorbidity with osteoarthritis suggests that old women with certain conditions might be treated using care services other than hospitalization (e.g., primary care).

\section{Methodological issues}

There is no consensus about how to best measure multimorbidity. According to the theory that the associations among morbidities must be involved when comorbidity rates exceed those that are statistically expected (coincidental) [34], hierarchical cluster analysis helps identify the conjunction between morbidities in a small population with a high prevalence of multimorbidity. Cluster score and cluster interactions have revealed synergistic effects on associative morbidities [13]. However, we realize that very different results may be obtained from the same data using different hierarchical clustering methods [23]. It is of great importance to relate the statistical results to real-life clinical practice so as to verify the interpretable clusters.

In the logistic regression models, the low $\mathrm{R}^{2}$ reminds us that reasons for the use of health services are multifaceted phenomena. According to Andersens' behavioral model, the use of health services is determined by predisposing characteristics (e.g., demographics, social structure, and health belief), enabling resources (e.g., the number of medical personnel and facilities), or a need for health care (health conditions including mortality, morbidity, and disability) [35]. Even if need is a dominant reason why older people use the ER [36,37], the measures of need as well as other contextual factors can vary [38]. In the present 
study, an increased number of GP visits reflected the medical needs of very old peoples. Greater use of assistive technology by older men provides information about their severe physical disability or illness because men are more reluctant than women to use assistive technology that brings them shame, embarrassment, and feelings of victimization [39]. Working status and education were measured separately instead of transforming to socioeconomic status. The effect of socio-economic status on the use of health service is not consistent in all studies $[37,40,41]$, probably owing to the use of different measures and the different financing of health care.

\section{Limitations}

A number of limitations of the present study should be mentioned. First, some morbidities (e.g., arthritis, anemia, and hip fracture) that were not included in the analysis had higher prevalence in other studies [13-15,42]. We cannot draw any gender-specific conclusion in the present study. Heterogeneity among populations needs to be considered. Second, diseases with no treatment and asymptomatic conditions could be missed by self-reported surveys and neglected by doctors when recording a medical history; e.g., anemia and osteoporosis. In particular, among non-participants having a high frequency of living in nursing homes, the extreme underestimation of dementia results in health services not being provided to individuals with cognitive impairment. Third, the financing and organization of health care in Sweden limits the generalizations of the findings as other countries may have different social or health care policy. Different welfare regimes affect the priorities of public resources and address inequality issues relating to the use of health services. Individuals with supplemental private health insurance may use private health services, but in this age group, the consumption of private health care is not common practice and it is not the focus of this paper.

\section{Conclusions}

We identified a vascular cluster, cardiopulmonary cluster and clusters related to aging for a population of 85-yearold Swedish men and women. A cardiac cluster and somatic-mental cluster were found in the men's cluster structure and a mental disease cluster in the women's. We further explored these clusters in relation to hospitalization and ER visits. Patterns of cardiac and pulmonary conditions explained hospitalization better than any single morbidity, while heart failure as a single morbidity was superior to multimorbidity patterns in explaining ER visits.

At a population level, identifying what type of morbidity cluster exists may facilitate the capture of potential hospital users. A holistic approach to examining the patterns of multimorbidity and their relationship to the use of health services in a given population will be useful for planning local health care, allocating and prioritizing resources, and geriatric practice.

\section{Competing interest}

The authors declared that they have no competing interest.

\section{Authors' contributions}

$\mathrm{DHJ}$ : retrieval of literature, analysis (design and performance) and interpretation of data, drafting of manuscript. WE: study concept and design, acquisition of subjects and data, manuscript development. MJ: study concept and design, data interpretation, and writing the final manuscript from the first draft. All authors read the manuscript and approved it for publication.

\section{Acknowledgments}

This work was supported by grants from The Health Research Council of the South-East of Sweden (FORSS-8888, FORSS-11636, FORSS-31811), the County Council of Östergötland (LIO-11877, LIO-31321, LIO-79951) and the Janne Elgqvist Family Foundation. We especially thank Mats Fredrikson (Linköping Academic Research (entre) for statistical consultations.

\section{Author details}

${ }^{1}$ Department of Clinical and Experimental Medicine, Division of Geriatrics, Faculty of Health Sciences, Linköping University, 58185 Linköping, Sweden. ${ }^{2}$ Department of Geriatric Medicine, County Council of Östergötland, Linköping, Sweden.

Received: 17 March 2013 Accepted: 18 October 2013

Published: 6 November 2013

\section{References}

1. Hernandez C, Jansa M, Vidal M, Nunez M, Bertran MJ, Garcia-Aymerich J, Roca J: The burden of chronic disorders on hospital admissions prompts the need for new modalities of care: a cross-sectional analysis in a tertiary hospital. QJM 2009, 102(3):193-202

2. Condelius A, Edberg AK, Jakobsson U, Hallberg IR: Hospital admissions among people $65+$ related to multimorbidity, municipal and outpatient care. Arch Gerontol Geriatr 2008, 46(1):41-55.

3. Friedman B, Jiang HJ, Elixhauser A, Segal A: Hospital inpatient costs for adults with multiple chronic conditions. Med Care Res Rev 2006, 63(3):327-346.

4. Wolff JL, Starfield B, Anderson G: Prevalence, expenditures, and complications of multiple chronic conditions in the elderly. Arch Intern Med 2002, 162(20):2269-2276.

5. Nagl A, Witte J, Hodek JM, Greiner W: Relationship between multimorbidity and direct healthcare costs in an advanced elderly population. Results of the PRISCUS trial. Z Gerontol Geriatr 2012, 45(2):146-154.

6. Case A, Paxson C: Sex differences in morbidity and mortality. Demography 2005, 42(2):189-214.

7. Vegda K, Nie JX, Wang L, Tracy CS, Moineddin R, Upshur RE: Trends in health services utilization, medication use, and health conditions among older adults: a 2-year retrospective chart review in a primary care practice. BMC Health Serv Res 2009, 9:217.

8. Collerton J, Davies K, Jagger C, Kingston A, Bond J, Eccles MP, Robinson LA, Martin-Ruiz C, Von Zglinicki T, James OF, Kirkwood TB: Health and disease in 85 year olds: baseline findings from the Newcastle 85+ cohort study. BMJ 2009, 339:b4904.

9. Nie JX, Wang L, Tracy CS, Moineddin R, Upshur RE: Health care service utilization among the elderly: findings from the Study to Understand the Chronic Condition Experience of the Elderly and the Disabled (SUCCEED project). J Eval Clin Pract 2008, 14(6):1044-1049.

10. Nagga K, Dong HJ, Marcusson J, Skoglund SO, Wressle E: Health-related factors associated with hospitalization for old people: comparisons of elderly aged 85 in a population cohort study. Arch Gerontol Geriatr 2012, 54(2):391-397.

11. Mathieson KM, Kronenfeld JJ, Keith VM: Maintaining functional independence in elderly adults: the roles of health status and financial resources in predicting home modifications and use of mobility equipment. Gerontologist 2002, 42(1):24-31.

12. Marengoni A, Winblad B, Karp A, Fratiglioni L: Prevalence of chronic diseases and multimorbidity among the elderly population in Sweden. Am J Public Health 2008, 98(7):1198-1200. 
13. John R, Kerby DS, Hennessy CH: Patterns and impact of comorbidity and multimorbidity among community-resident American Indian elders. Gerontologist 2003, 43(5):649-660.

14. Marengoni A, Rizzuto D, Wang HX, Winblad B, Fratiglioni L: Patterns of chronic multimorbidity in the elderly population. J Am Geriatr Soc 2009, 57(2):225-230.

15. Formiga F, Ferrer A, Sanz H, Marengoni A, Alburquerque J, Pujol R, on behalf of the Octabaix study members: Patterns of comorbidity and multimorbidity in the oldest old: The Octabaix study. Eur J Intern Med 2013, 24(1):40-44.

16. Swedish Institute: Elderly care in Sweden. Stockholm: Swedish Institute; 2007:FS8.

17. MISSOC: Social protection in the Member States of the European Union, of the European Economic Area and in Switzerland: situation on 1 January 2007. Brussels: European Commission; 2008.

18. Dutton DB, Levine S: Socioeconomic status and health: overview, methodological critique, and reformulation. In In pathways to health: The role of social factors. 1st edition. Edited by Bunker JP, Gomby DS, Kehrer BH. Menlo Park, CA: Henry J Kaiser Family Foundation; 1989:29-69.

19. The EuroQol Group: EuroQol-a new facility for the measurement of health-related quality of life. Health Policy 1990, 16(3):199-208.

20. World Health Organization: International Statistical Classification of Diseases and Related Health Problems, $10^{\text {th }}$ Revision. Geneva: World Health Organization; 1992

21. Tan $P$, Kumar $V$, Srivastava J: Selecting the right objective measure for association analysis. Inf Syst 2004, 29:293-313.

22. Yule GU: On the association of attributes in statistics: with illustrations from the material of the childhood society, \&c. Philosophical Transactions of the Royal Society of London. Series A, Containing Papers of a Mathematical or Physical Character 1900, 194:257-319.

23. Everitt BS, Landau S, Leese M, Stahl D: Cluster Analysis. 5th edition. United Kingdom: John Wiley \& Sons, Ltd; 2011.

24. Nagelkerke NJD: A note on a general definition of the coefficient of determination. Biometrika 1991, 78:691-692.

25. Maggi S, Siviero P, Gonnelli S, Schiraldi C, Malavolta N, Nuti R, Crepaldi G, EOLO Study Group: Osteoporosis risk in patients with chronic obstructive pulmonary disease: the EOLO study. J Clin Densitom 2009, 12(3):345-352.

26. Gjerde B, Eagan TML, Hardie JA, Bakke PS: Which disease characteristics in copd are related to comorbidities? [abstract]. Am J Respir Crit Care Med 2009, 179:A1454

27. Vasudev K, Gupta AK: Incontinence and mood disorder: is there an association? BMJ Case Rep 2010, 2010. bcr07.2009.2118. Epub 2010 Feb 8.

28. Ko Y, Lin SJ, Salmon JW, Bron MS: The impact of urinary incontinence on quality of life of the elderly. Am J Manag Care 2005, 11(4 Suppl):S103-111.

29. Teunissen D, Van Den Bosch W, Van Weel C, Lagro-Janssen T: "It can always happen": the impact of urinary incontinence on elderly men and women. Scand J Prim Health Care 2006, 24(3):166-173.

30. Turner-Stokes L, Frank AO: Urinary incontinence among patients with arthritis-a neglected disability. J R Soc Med 1992, 85(7):389-393.

31. Yancik R, Ganz PA, Varricchio CG, Conley B: Perspectives on comorbidity and cancer in older patients: approaches to expand the knowledge base. J Clin Oncol 2001, 19(4):1147-1151

32. Glynn LG, Valderas JM, Healy P, Burke E, Newell J, Gillespie P, Murphy AW: The prevalence of multimorbidity in primary care and its effect on health care utilization and cost. Fam Pract 2011, 28(5):516-523.

33. Freund T, Kunz CU, Ose D, Szecsenyi J, Peters-Klimm F: Patterns of multimorbidity in primary care patients at high risk of future hospitalization. Popul Health Manag 2012, 15(2):119-124.

34. Batstra L, Bos EH, Neeleman J: Quantifying psychiatric comorbidity-lessions from chronic disease epidemiology. Soc Psychiatry Psychiatr Epidemiol 2002, 37(3):105-111.

35. Andersen RM: National health surveys and the behavioral model of health services use. Med Care 2008, 46(7):647-653

36. McCusker J, Karp I, Cardin S, Durand P, Morin J: Determinants of emergency department visits by older adults: a systematic review. Acad Emerg Med 2003, 10(12):1362-1370.

37. Walter-Ginzburg A, Chetrit A, Medina C, Blumstein T, Gindin J, Modan B: Physician visits, emergency room utilization, and overnight hospitalization in the old-old in Israel: the cross-sectional and longitudinal aging study (CALAS). J Am Geriatr Soc 2001, 49(5):549-556.

38. Babitsch B, Gohl D, Von Lengerke T: Re-revisiting Andersen's behavioral model of health services use: a systematic review of studies from 1998-2011. Psychosoc Med 2012, 9:Doc11

39. Haggblom-Kronlof G, Sonn U: Use of assistive devices-a reality full of contradictions in elderly persons' everyday life. Disabil Rehabil Assist Technol 2007, 2(6):335-345.

40. Khan Y, Glazier RH, Moineddin R, Schull MJ: A population-based study of the association between socioeconomic status and emergency department utilization in Ontario, Canada. Acad Emerg Med 2011, 18(8):836-843.

41. Naughton C, Drennan J, Treacy P, Fealy G, Kilkenny M, Johnson F, Butler M: The role of health and non-health-related factors in repeat emergency department visits in an elderly urban population. Emerg Med J 2010, 27(9):683-687.

42. Drewes YM, Den Elzen WP, Mooijaart SP, De Craen AJ, Assendelft WJ, Gussekloo J: The effect of cognitive impairment on the predictive value of multimorbidity for the increase in disability in the oldest old: the Leiden 85-plus Study. Age Ageing 2011, 40(3):352-357.

doi:10.1186/1471-2318-13-120

Cite this article as: Dong et al:: Multimorbidity patterns of and use of health services by Swedish 85-year-olds: an exploratory study. BMC Geriatrics 2013 13:120.

\section{Submit your next manuscript to BioMed Central and take full advantage of:}

- Convenient online submission

- Thorough peer review

- No space constraints or color figure charges

- Immediate publication on acceptance

- Inclusion in PubMed, CAS, Scopus and Google Scholar

- Research which is freely available for redistribution 